\title{
Bone histoquantitative findings and histochemical staining reactions for aluminium in chronic renal failure patients treated with haemodialysis fluids containing high and low concentrations of aluminium
}

\author{
J McCLURE, NL FAZZALARI*, RG FASSETT $\dagger$, DJ PUGSLEY $\dagger$ \\ From the ${ }^{*}$ Division of Tissue Pathology, IMVS, Adelaide and the $\nmid$ Renal Unit, Queen Elizabeth Hospital, \\ Woodville, South Australia
}

SUMMARY A total of 112 undecalcified bone biopsies from 67 patients under treatment for chronic renal failure by maintenance haemodialysis was available for retrospective study. The patients were divided into three groups. Group I (15 cases) had been dialysed for the majority of the time in their own homes with a fluid containing a low concentration of aluminium. Group II (28 cases) had been dialysed exclusively in hospital (prior to 1978) with a fluid containing a high concentration of aluminium and group III (24 cases) had been treated exclusively in hospital (from 1978 onwards) with a fluid of low aluminium concentration. The tissues from these groups were subjected to histoquantitative assessment and stained by a histochemical technique to demonstrate aluminium salt.

In group II, $71.4 \%$ of cases showed positive aluminium staining reactions (at the osteoid/ mineralised tissue interface) compared to $26.6 \%$ in group I and $37.5 \%$ in group III. Staining reactions were also more extensive in group II cases. The osteoid volume was significantly increased and the calcification front extents significantly decreased in group II compared to both groups I and III. A comparison of histochemically positive with negative cases in each group showed a significantly increased osteoid volume and significantly decreased calcification fronts in the positive cases. It was, therefore, concluded that haemodialysis against a fluid containing a high concentration of aluminium leads to intraosseous aluminium accumulation of greater degree in a larger number of patients than a fluid with low aluminium content and that there is an accompanying osteomalacia manifest by an increase in osteoid volume together with diminution in the extent of the calcification fronts.

There is an increasing body of evidence that skeletal aluminium accumulation is an important aetiological factor in a form of renal osteodystrophy associated with haemodialysis. ${ }^{1}$ This is manifest as a progressive development of a severe form of osteomalacia with bone pain, fractures, skeletal deformity and a myopathy. ${ }^{2}$ This has been designated as atypical renal osteomalacia by Cochran. ${ }^{3}$ Histologically there are wide osteoid seams associated with inert osteoblasts and the osteoid/mineralised tissue junction is occupied by linearly disposed accumulations of aluminium. ${ }^{45}$

Accepted for publication 10 May 1983
Serum aluminium concentrations rise after haemodialysis and the magnitude of the rise is determined by the aluminium concentration in the dialysis fluid. ${ }^{2}$ A major contributor to the high aluminium concentration in the dialysis fluid is the aluminium sulphate added as a flocculating agent to the local water supply as part of the process of purification.

All maintenance haemodialysis patients under the care of the Renal Unit, Queen Elizabeth Hospital, Adelaide, are initially dialysed in hospital and then continue haemodialysis either in their own homes or in the hospital. Since 1976 the home dialysis facilities have used water treated by reverse osmosis. However, this process was not introduced in the 
hospital until February 1978. Bone biopsies were therefore available from three groups of patients. In group I were those on home dialysis. Their biopsies were taken during the period of home dialysis and not during their period of dialysis in hospital (which took place prior to 1978). In group II were patients dialysed exclusively in hospital prior to 1978 and in group III those who were dialysed exclusively in hospital after February 1978. Patients who had a dialysis encephalopathy-like syndrome were excluded from the study and have been the subject of a previous report. ${ }^{5}$ A comparison of several histoquantitative bone biopsy parameters for these three groups, together with a histochemical study of the aluminium distribution within the biopsy material was made to determine if any differences existed between the groups.

\section{Material and methods}

A total of 112 bone biopsies from 67 patients in chronic renal failure and under treatment by intermittent haemodialysis was available for retrospective study. Each biopsy had been taken from the left anterior iliac crest $20 \mathrm{~mm}$ to $40 \mathrm{~mm}$ behind the anterior superior spine. Repeat biopsies were taken close to, but separate from, the initial biopsy sites. Multiple thin $(7 \mu \mathrm{m})$, undecalcified, sections from each biopsy were stained by the von Kossa technique with either the van Gieson method or haematoxylin and eosin as counter stains. A minimum of five sections (chosen at random) from each biopsy was stained by the aluminon (Irwin) technique $^{6}$ which (under appropriate conditions ${ }^{5}$ ) is known specifically to demonstrate aluminium.

Using the van Gieson counter-stained sections the total cancellous bone volume and osteoid volume were estimated using the Quantimet image analysis computer. ${ }^{78}$ Calcification fronts were demonstrated in undecalcified sections by haematoxylin staining 9 (Raina method) and their extents expressed as a percentage of the osteoid seams bearing a front. Resorbing surfaces were estimated as the percentage of the trabecular surface occupied by either active (with an osteoclast) or inactive (without an osteoclast) resorption sites.

In those biopsies in which there was a positive aluminon reaction (seen as a red/purple line at the osteoid/mineralised tissue junction), the extent of the reaction was quantified using an eyepiece graticule with 21 grid lines. Fields were examined at a magnification of $\times 150$ and 100 non-overlapping fields were examined at random in the available sections of each biopsy. Line intersect techniques were applied and the extent of the linear positive reaction expressed as (i) a percentage of the osteoid seams and (ii) a percentage of the total trabecular surface.

The patients were segregated into three mutually exclusive groups. In group I (home dialysis) there were 15 patients ( 7 male, 8 female), in group II (hospital dialysis pre 1978) 28 (14 male, 14 female) and, in group III (hospital dialysis post 1978) 24 (17 male, 7 female). The number of biopsies available per group was 42,28 and 42 . In each group the histoquantitative data were treated in a collective fashion and a number of statistical analyses performed. All the biopsies were taken more than six months after the start of haemodialysis and consecutive biopsies were included only if they had been taken at least six months apart. Biopsies from the home dialysis patients were taken more than six months after the change over from hospital to home dialysis. The data were analysed using parametric statistical models. Student's $t$ test was used to compare the treatment groups. A normal distribution was assumed for the data, but the group variances were taken as unequal and unknown. Hence the $t$ statistic was calculated using the formula:

$$
t=\frac{(\overline{\mathrm{x}}-\overline{\mathrm{y}})-\mu_{\mathrm{o}}}{\left[\frac{\mathrm{s}_{1}{ }^{2}}{\mathrm{n}_{1}}+\frac{\mathrm{s}_{2}{ }^{2}}{\mathrm{n}_{2}}\right]^{\frac{1}{2}}}
$$

where $\overline{\mathbf{x}}$ and $\bar{y}$ are the group means, $\mu_{\mathrm{o}}$ the diffe $\varrho \overline{0}$ ence of the distribution means, $s_{1}{ }^{2}$ and $s_{2}{ }^{2}$ the calcus. lated variance for each group and $n_{1}$ and $n_{2}$ the number in each group. The degrees of freedom $(\nu)$ is weighted average, thus: ${ }^{10}$

$$
\begin{aligned}
& \frac{1}{\nu}=\frac{1}{n_{1}-1}\left(\frac{s_{1}{ }^{2} / n_{1}}{s_{1}{ }^{2} / n_{1}+s_{2}{ }^{2} / n_{2}}\right)^{2} \\
& +\frac{1}{n_{2}-1}\left(\frac{s_{2}{ }^{2} / n_{2}}{s_{1}{ }^{2} / n_{1}+s_{2}{ }^{2} / n^{2}}\right)^{2}
\end{aligned}
$$

Statistical significance in the study was set at the critical $p$ value of $0 \cdot 05$.

\section{Results}

Table 1 shows the mean and standard error of the mean (SEM) of the age (yr), duration of dialysis (months), total cancellous bone volume, osteoid volume, calcification front extent and resorbing sur- os face of the three treatment groups. Comparisons of $N$ these values for each parameter are also shown. For N group I the periods of dialysis against non-reverse 0 osmosis fluid (in hospital) and dialysis against reverse osmosis fluid (at home) are shown sepa- $\frac{\mathscr{D}}{\Phi}$ rately with comparisons only being made with the $\stackrel{\infty}{+}$ reverse osmosis fluid period of dialysis. Group I 0 (home dialysis) patients were significantly younger

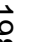


Table 1 Mean and (SEM) of age, duration of dialysis (reverse osmosis and non-reverse osmosis periods separated in Group I) and the four histoquantitative parameters. Also included are comparisons of these values and the level of significance of observed differences (NS = not significant). For comparison of duration of dialysis the reverse osmosis period only is used for Group I.

\begin{tabular}{|c|c|c|c|c|c|c|}
\hline & $\begin{array}{l}\text { Age } \\
\text { (years) }\end{array}$ & $\begin{array}{l}\text { Duration of dialysis } \\
\text { (months) }\end{array}$ & $\begin{array}{l}\text { Total bone } \\
\text { volume } \\
\text { (\% cancellous } \\
\text { space) }\end{array}$ & $\begin{array}{l}\text { Osteoid volume } \\
\text { (\% cancellous } \\
\text { space) }\end{array}$ & $\begin{array}{l}\text { Calcification } \\
\text { fronts } \\
\text { (\% osteoid } \\
\text { surface) }\end{array}$ & $\begin{array}{l}\text { Resorbing } \\
\text { surfaces } \\
\text { (\% trabecular } \\
\text { surface) }\end{array}$ \\
\hline $\begin{array}{l}\text { Group I } \\
\text { (home dialysis) }\end{array}$ & $42 \cdot 6(4 \cdot 0)$ & $\begin{array}{l}\text { reverse osmosis } \\
52 \cdot 8(2 \cdot 4) \\
\text { non-reverse } \\
\text { osmosis } \\
28 \cdot 0(7 \cdot 8)\end{array}$ & $31 \cdot 8(2 \cdot 2)$ & $1.9(0.3)$ & $71 \cdot 3(2 \cdot 9)$ & $15 \cdot 6(1 \cdot 6)$ \\
\hline $\begin{array}{l}\text { Group II } \\
\text { (hospital dialysis) } \\
\text { (pre 1978) }\end{array}$ & $52 \cdot 2(3 \cdot 5)$ & $26 \cdot 7(3 \cdot 4)$ & $30 \cdot 0(2 \cdot 3)$ & $4 \cdot 1(0 \cdot 6)$ & $44 \cdot 4(5 \cdot 7)$ & $11 \cdot 6(1 \cdot 3)$ \\
\hline $\begin{array}{l}\text { Group III } \\
\text { (hospital dialysis) } \\
\text { (post 1978) }\end{array}$ & $48 \cdot 5(2 \cdot 9)$ & $24 \cdot 2(2 \cdot 0)$ & $23 \cdot 4(1 \cdot 0)$ & $0.9(0.2)$ & $79 \cdot 5(2 \cdot 5)$ & $15 \cdot 0(1 \cdot 4)$ \\
\hline $\begin{array}{l}\text { Group I v } \\
\text { Group II }\end{array}$ & $\begin{array}{l}\mathrm{I}<\text { II } \\
\mathrm{p}<0.025\end{array}$ & $\begin{array}{l}\text { I }>\text { II } \\
\text { p }<0.025 \text { (reverse } \\
\text { osmosis water) }\end{array}$ & NS & $\begin{array}{l}\mathrm{I}<\mathrm{II} \\
\mathrm{P}<0.005\end{array}$ & $\begin{array}{l}\mathrm{I}>\mathrm{II} \\
\mathrm{p}<0.0005\end{array}$ & $\begin{array}{l}\text { I }>\text { II } \\
\mathrm{p}<0.05\end{array}$ \\
\hline $\begin{array}{l}\text { Group I } v \\
\text { Group III }\end{array}$ & NS & $\begin{array}{l}\text { I }>\text { III } \\
\text { P }<0.025\end{array}$ & $\begin{array}{l}\text { I }>\text { III } \\
\text { p }<0.05\end{array}$ & $\begin{array}{l}\text { I }>\text { III } \\
\mathrm{p}<0.01\end{array}$ & $\begin{array}{l}\mathrm{I}<\mathrm{III} \\
\mathrm{p}<0.025\end{array}$ & NS \\
\hline $\begin{array}{l}\text { Group II } v \\
\text { Group III }\end{array}$ & NS & NS & NS & $\begin{array}{l}\text { II }>\text { III } \\
\mathrm{p}<0.0005\end{array}$ & $\begin{array}{l}\text { II }<\text { III } \\
\mathrm{p}<0.0005\end{array}$ & $\begin{array}{l}\text { II }<\text { III } \\
\mathrm{p}<0.05\end{array}$ \\
\hline
\end{tabular}

than group II (hospital dialysis pre 1978), but there was no significant difference between groups I and III (hospital dialysis post 1978) and groups II and III. Group I had been on haemodialysis with reverse osmosis fluid approximately twice as long as group II or group III. There was no significant difference in duration of dialysis between groups II and III.

Osteoid volume was highest overall in group II and also significantly greater in group I compared to group III. Calcification front extents were least in group II and significantly lower in group I compared to group III. Resorbing surfaces were greater in group I compared to group II, group III compared to group II and not significantly different when group I was compared to group III.

Positive aluminon staining reactions were present in four of the 15 cases of group I. They were present in five of 42 available specimens being present in two consecutive biopsies of one of the cases. With this exception positive reactions were present in the last biopsy specimen in each case (ie after the maximum period of dialysis of that patient). In group II positive reactions were present in 20 of the 28 specimens available. In group III positive reactions

Table 2 Mean and (SEM) of duration of dialysis (reverse osmosis water dialysis period in group I), osteoid volume and calcification fronts for each treatment group divided into two subgroups with either positive or negative Aluminon staining reactions and the comparison of the mean values of the two subgroups.

\begin{tabular}{|c|c|c|c|}
\hline & $\begin{array}{l}\text { Duration of dialysis } \\
\text { (months) }\end{array}$ & $\begin{array}{l}\text { Osteoid volume } \\
\text { (\% cancellous space) }\end{array}$ & $\begin{array}{l}\text { Calcification fronts } \\
\text { (\% osteoid surface) }\end{array}$ \\
\hline $\begin{array}{l}\text { Group I Aluminon }+\mathrm{ve} v-\mathrm{ve} \\
\end{array}$ & 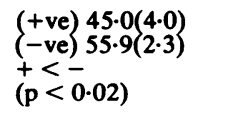 & $\begin{array}{l}2.2(0.9) \\
1 \cdot 7(0.3) \\
\text { NS }\end{array}$ & $\begin{array}{l}69 \cdot 6(8 \cdot 3) \\
74 \cdot 1(2 \cdot 6) \\
\text { NS }\end{array}$ \\
\hline $\begin{array}{l}\text { Group II Aluminon } \\
\qquad \mathrm{ve} v-\mathrm{ve}\end{array}$ & $\begin{array}{l}\text { (+ve) } 27 \cdot 5(3 \cdot 3) \\
\text { NS } 19 \cdot 3(5 \cdot 9) \\
\text { NS }\end{array}$ & $\begin{array}{l}6.0(1.3) \\
2.6(0.8) \\
+>- \\
(\mathrm{p}<0.04)\end{array}$ & $\begin{array}{l}33 \cdot 1(6 \cdot 3) \\
62 \cdot 2(13 \cdot 3) \\
+<- \\
(\mathrm{p}<0 \cdot 01)\end{array}$ \\
\hline $\begin{array}{l}\text { Group III Aluminon } \\
\qquad+v e v-v e\end{array}$ & $\begin{array}{l}\left(\begin{array}{l}+v e) \\
-v e \\
-v \cdot 1(3 \cdot 5 \\
\text { NS }\end{array}\right. \\
\text { 24.1(2.6) }\end{array}$ & $\begin{array}{l}1.3(0.3) \\
0.7(0.2) \\
+>- \\
(p<0.05)\end{array}$ & $\begin{array}{l}66.0(4.5) \\
85.5(2 \cdot 1) \\
+<- \\
(p<0.004)\end{array}$ \\
\hline
\end{tabular}


Table 3 Mean and (SEM) of the duration of dialysis of group I cases indicating the periods of dialysis with non-reverse osmosis fuid and reverse osmosis fuid for all cases in the group and Aluminon positive and negative subgroups.

\begin{tabular}{lcl}
\hline & $\begin{array}{l}\text { Duration of dialysis } \\
\text { with non-reverse } \\
\text { osmosis fuid } \\
\text { (months) }\end{array}$ & $\begin{array}{l}\text { Duration of dialysis } \\
\text { with reverse } \\
\text { osmosis fuid } \\
\text { (months) }\end{array}$ \\
\hline All cases & $28 \cdot 0(7 \cdot 8)$ & $52 \cdot 8(2 \cdot 4)$ \\
Aluminon +ve cases & $7 \cdot 5(1 \cdot 2)$ & $45 \cdot 0(4 \cdot 0)$ \\
Aluminon - ve cases & $36 \cdot 2(9 \cdot 8)$ & $55 \cdot 9(2 \cdot 3)$ \\
\hline
\end{tabular}

were present in nine of the 24 cases ( 12 of 42 specimens). Three of the nine cases had two consecutive biopsies exhibiting positive reactions. In these the biopsies were the last and second last taken and in the other six cases they were the last taken.

In each group aluminon positive and negative cases were segregated and the subgroups compared with respect to duration of dialysis, osteoid volume and calcification front extent. These comparisons are shown in Table 2. In group I there was no significant difference with respect to osteoid volume and calcification front extent. In groups II and III the osteoid volume was significantly greater and calcification front extent significantly less in the aluminon positive cases.

A between group comparison was made of the aluminon positive and negative cases within each group. The comparisons were made with respect to duration of dialysis (reverse osmosis fluid), osteoid volume and calcification front extent. The results are shown in Table 4. For the Irwin positive cases there
Table 5 Mean and (SEM) of the extent of positive Aluminon reactions expressed as a percentage of the osteoid seams and of the total trabecular surface bearing a linear positive reaction. A comparison of mean values, together with the level of significance of differences observed, is given.

\begin{tabular}{|c|c|c|}
\hline & \multicolumn{2}{|c|}{ Positive Aluminon reactions } \\
\hline & $\%$ of osteoid seams & $\begin{array}{l}\text { \% of trabecular } \\
\text { surface }\end{array}$ \\
\hline Group I & $29 \cdot 3(1 \cdot 1)$ & $18 \cdot 4(4 \cdot 3)$ \\
\hline Group II & $43 \cdot 3(4 \cdot 0)$ & $36 \cdot 9(3 \cdot 5)$ \\
\hline Group III & $28 \cdot 2(2 \cdot 4)$ & $22 \cdot 9(2 \cdot 3)$ \\
\hline $\begin{array}{l}\text { Group I } v \text { group II } \\
\text { Group I } v \text { group III } \\
\text { Group II } v \text { group III }\end{array}$ & $\begin{array}{l}\mathrm{I}<\mathrm{II}(\mathrm{p}<0.04) \\
\mathrm{NS} \\
\text { II }>\text { III }(\mathrm{p}<0.003)\end{array}$ & $\begin{array}{l}\text { I }<\text { II }(p<0.01) \\
\text { IS } \\
\text { II }>\text { III }(p<0.002)\end{array}$ \\
\hline
\end{tabular}

was a greater period of dialysis (with reverse $\stackrel{\infty}{\rightarrow}$ osmosis fluid) in group I compared to both groups II and III, but no significant difference between groups II and III.

Osteoid volume was greatest in group II cases and significantly higher in that group when compared to groups I and III. There was no significant difference in osteoid volume in group I compared to group III. Calcification front extents were significantly less \&n $\overrightarrow{0}$ group II cases compared to groups I and III. Thefecu was no significant difference between the latter. Färo the negative cases group I had a greater period reverse osmosis fluid dialysis compared to groups II and III, but there was no significant difference bet-⿳亠丷厂 ween groups II and III. There was no significanto difference between the osteoid volume of the groups I and II, but the group I value was greater than

Table 4 Comparison of Aluminon positive and negative cases of the three treatment groups with respect to duration of dialysis, osteoid volume and calcification fronts.

\begin{tabular}{|c|c|c|c|}
\hline & \multicolumn{3}{|l|}{ Aluminon-positive cases } \\
\hline & Duration of dialysis (months) & $\begin{array}{l}\text { Osteoid volume (\% cancellous } \\
\text { space) }\end{array}$ & $\begin{array}{l}\text { Calcification fronts (\% osteoid } \\
\text { surface) }\end{array}$ \\
\hline Group I $v$ group II & $\begin{array}{l}\text { I }>\text { II } \\
\mathrm{p}<0.05\end{array}$ & $\begin{array}{l}\mathrm{I}<\mathrm{II} \\
\mathrm{p}<0.02\end{array}$ & $\begin{array}{l}\mathrm{I}>\mathrm{II} \\
\mathrm{p}<0.01\end{array}$ \\
\hline Group I $v$ group III & $\begin{array}{l}\text { I }>\text { III } \\
\mathrm{p}<0.008\end{array}$ & NS & NS \\
\hline Group II $v$ group III & NS & $\begin{array}{l}\text { II }>\text { III } \\
\mathrm{p}<0.002\end{array}$ & $\begin{array}{l}\text { II }<\text { III } \\
\mathrm{p}<0.0002\end{array}$ \\
\hline Group I $v$ group II & $\begin{array}{l}\text { Aluminon-negative cases } \\
\text { I }>\text { II } \\
\mathrm{p}<0.0001\end{array}$ & NS & NS \\
\hline Group I $v$ group III & $\begin{array}{l}\text { I }>\text { III } \\
\text { p }<0.0001\end{array}$ & $\begin{array}{l}\text { I }>\text { III } \\
\mathrm{p}<0.005\end{array}$ & $\begin{array}{l}\mathrm{I}<\text { III } \\
\mathrm{p}<0.0005\end{array}$ \\
\hline Group II $v$ group III & NS & $\begin{array}{l}\text { II }>\text { III } \\
\mathrm{p}<0.001\end{array}$ & $\begin{array}{l}\text { II }<\text { III } \\
\text { p }<0.003\end{array}$ \\
\hline
\end{tabular}


group III and group II was significantly greater than group III. There was no difference in calcification front extent, group I compared to group II, but both groups I and II had reduced calcification front extents when compared to group III.

The extents of the aluminon-positive reactions expressed as a percentage of the osteoid seams and of the total trabecular surface bearing a positive reaction are given in Table 5 together with intergroup comparisons. The reaction extents are significantly greater in group II than in groups I and III with no significant difference between the latter two.

\section{Discussion}

Not only did more cases in group II $(71.4 \%)$ show positive aluminon reactions when compared to group I (26.6\%) and group III (37.5\%), but staining reactions were also more extensive (as estimated by line intersect techniques) in group II cases. Ott et $a l^{11}$ quantified the surface lengths of aluminon positive reactions with an XY digitiser in their retrospective study of biopsies from cases of renal osteodystrophy. The results were recorded as the percentage of the total trabecular mineralised bone surface covered by aluminium and as the absolute length in $\mathrm{mm}$ per $\mathrm{mm}^{2}$ of tissue area (including bone and marrow). The two measurements had a correlation coefficient of 0.96 in 41 samples $(p<0.001)$. The second measurement had a correlation coefficient of $0.81(p<0.001)$ with bone aluminium content ( $\mathrm{mg} / \mathrm{kg}$ dry weight) measured by flameless atomic absorption spectrophotometry in a separate sample of 96 specimens. Therefore the line intersect techniques used in the present study which were originally developed to estimate the extent of a histochemical reaction give a good indication of the amount of aluminium present since they are essentially similar to the first measurement used by Ott et al. ${ }^{11}$ These workers segregated their cases on the basis of the type of renal osteodystrophy observed and noted that $70 \%$ of their osteomalacic samples had heavy aluminium staining. It is not possible to make direct comparison with the present study since segregation here was not by diagnostic category but by treatment regimen. However, if group II cases are taken, on a mean basis, to be osteomalacic (the difficulty in diagnosing histological osteomalacia in renal bone disease will be considered later) then a percentage $(71.4 \%)$ practically identical to that of Ott et al shows positive aluminon reactions.

In the context of the present study it is reasonable to conclude that dialysis with non-reverse osmosis fluid is associated with greater intraosseous aluminium accumulation in a larger number of indi- viduals than is dialysis with reverse osmosis fluid. The origin of a major part of this aluminium is illustrated by noting the aluminium content of the Adelaide tap water. Thus in 1975 the use of flocculation resulted in an aluminium concentration of $1.23 \mathrm{mg} / \mathrm{l}$. The concentration in the dialysate used in the Renal Unit (Queen Elizabeth Hospital) was $1.15 \mathrm{mg} / \mathrm{l}$. In February 1978 a reverse osmosis facility was installed in the Renal Unit. At this time the tap water content was $1.0 \mathrm{mg} / \mathrm{l}$ and after reverse osmosis the dialysate content was reduced to less than $0.1 \mathrm{mg} / \mathrm{l}$. In late 1980 the aluminium content of the tap water was further reduced to $0.01-0.02 \mathrm{mg} / 1$ with a dialysis content after reverse osmosis of $0.005-0.01 \mathrm{mg} / \mathrm{l}$. All biopsies in group 'III were taken during the period from February 1978 until the date of further reduction in aluminium content.

Group I was particularly interesting since during the time of dialysis at home reverse osmosis fluid was used and bone biopsies were only available from this period. All cases had been dialysed against non-reverse osmosis fluid in hospital before changing over to home dialysis. The mean period of their hospital dialysis was $28(\mathrm{SEM}=7 \cdot 8)$ months which was not significantly different from that of group II $(26.7(3.41))$ and group III $(24.2(2.01))$. However, their period of reverse osmosis water dialysis was much greater $(52.8(2.4)$ months). In those cases (four out of 15) which did develop positive Irwin reactions these appeared after the maximum period of dialysis with reverse osmosis fluid and not after the change over from non-reverse osmosis to reverse osmosis fluid (biopsies were not available until at least six months had elapsed from the change over). This might be taken to indicate that the accumulation occurred during the period of reverse osmosis fluid dialysis and not as a consequence of the previous non-reverse osmosis fluid treatment. However, Ellis $e^{2}$ al $^{12}$ have shown (by neutron activation analysis) that aluminium persisted in some patients for many years after successful renal transplantation. The development of positive staining in our cases might be due to sampling error resulting from a patchy distribution by aluminium in bone or to a transfer of aluminium to bone from a storage site in another organ or tissue.

Ellis $e t$ al also noted that, although no statistically significant relation was found between the mineralisation status of bone and bone aluminium concentrations, patients dialysed for the longest periods tended to be those with the highest concentrations of aluminium, osteomalacia and dialysis encephalopathy. In the present studies the aluminon positive cases in group I had been on reverse osmosis fluid dialysis for a significantly shorter period (45.0 (4.0) months) than the aluminon nega- 
tive cases $(55.9(2 \cdot 3)$ months). In groups II and III there was no significant difference in the period of dialysis of aluminon positive compared to aluminon-negative cases. Therefore, the duration of dialysis does not determine the presence of histochemically demonstrable aluminium in bone tissue.

The development of aluminon positive reactions in some of the patients being dialysed with reverse osmosis fluid also raises the question of the origin of the aluminium. The dialysate aluminium level of $<0.1 \mathrm{mg} / \mathrm{l}$ after reverse osmosis might be considered to be still too high and uptake might well have continued. In addition, early studies had reported hyperaluminaemia after the ingestion of aluminium containing compounds. ${ }^{13}$ These studies have been criticised on technical grounds, but it has been shown more recently that patients in chronic renal failure and dialysed against low concentrations of aluminium do show hyperaluminaemia after ingestion of aluminium hydroxide. ${ }^{14}$ Therefore, oral aluminium hydroxide is a possible source of osseous aluminium. ${ }^{15}$ Other possible sources include ingestion of food contaminated by aluminium cooking utensils and malfunction of the reverse osmosis membrane.

A consideration of the characteristics of the three treatment groups indicated that group II and group III patients had similar periods of dialysis and were of comparable age. Group I cases were younger and had a considerably longer period of total dialysis (and presumably chronic renal failure). These patients were, therefore, a more selected group. They also had the highest mean total cancellous bone volume suggesting a trend towards osteosclerosis. Their osteoid volume was significantly less than in group II, but significantly greater than in group III. However, the calcification front extent in group I were not diminished $(<70 \%)$ suggesting that the hyperosteoidosis was not due to a defect in the mineralisation process. (For comparison purposes the normal reference range used in Adelaide is given in Table 6.)

In attempting to elucidate the effect of aluminium accumulation in bone it is instructive to compare groups II and III. In group II osteoid volume was significantly greater and calcification front extent significantly less than in group III.

The coupling of these parameters in an inverse fashion suggests a defect in the mineralisation process. This might be taken to indicate the presence of osteomalacia, although in the context of chronic renal failure it is difficult to evolve an entirely satisfactory histological definition of osteomalacia. ${ }^{1}$ The significance of the calcification front extent estimations depends on the validity of the method used to
Table 6 These normal values are derived from iliac crest biopsies of 37 healthy subjects resident in the Adelaide area $\vec{乛}$ (13 males, 24 females) with no previous significant medical histories, no evidence of metabolic bone disease and whose $\overrightarrow{\vec{F}}$ biochemical parameters including those of calcium metabolism and renal function were within normal limits.

\begin{tabular}{|c|c|}
\hline Parameter & Normal values \\
\hline $\begin{array}{l}\text { Total cancellous bone volume } \\
\text { (\% cancellous space) }\end{array}$ & $\begin{array}{l}<50 \text { years of age } 15-29 \% \\
\geqslant 50 \text { years of age } \quad 9-20 \%\end{array}$ \\
\hline $\begin{array}{l}\text { Osteoid volume } \\
\text { (\% cancellous space) }\end{array}$ & $<0.3 \%$ \\
\hline $\begin{array}{l}\text { Calcification front extents } \\
\text { (\% osteoid surface) }\end{array}$ & $>70 \%$ \\
\hline $\begin{array}{l}\text { Total resorbing surface } \\
\text { (\% total trabecular surface) }\end{array}$ & $<20 \%$ \\
\hline
\end{tabular}

demonstrate the calcification front. Recent work in our laboratory has shown that the Raina method $\dot{\sim}$ correlates highly with tetracycline labelling in vivo. ${ }^{1000}$ Therefore, it is reasonable to conclude thato increased osteoid volume and decreased. calcification front extent indicates an osteomalacia. $z$ It is further concluded that increased histochemi-O cally demonstrable aluminium is accompanied by an increased osteoid volume and decreasedo calcification front extent. An association is thereby= suggested, but not necessarily proven. However, has been shown in the experimental animal that administration of aluminium chloride is followed $\overline{6}$. the accumulation of aluminium in bone and the development of osteomalacia. ${ }^{12}$ Obviously the accumulation of aluminium at the calcification front site could inhibit mineralisation possibly by the pre-ब ferential formation of aluminium phosphates.

The comparison of aluminon positive and nega-oำ tive cases within each group produced results which must be interpreted cautiously since the numbers in some subgroups were small. However, within each group aluminon positive cases had significantlyo higher osteoid volume and significantly lowerocalcification front extent values. These findings. might also be taken to indicate that the presence of histochemically demonstrable aluminium is accompanied by increased osteoid volume and diminished응 calcification front extent values. Comparison of the aluminon positive subgroups across the three treatment groups showed that the osteoid volume values $\tilde{N}$ were higher and calcification front extent values. lower in group II cases compared to those of groups 0 I and II (there was no significant difference between N cases of groups I and III). Again this might be con-O strued as evidence of an association between his ro tochemically demonstrable aluminium and a mineralisation defect, except that a similar effect $\stackrel{\infty}{+}$ was found when aluminon negative cases were simi- 0 larly compared. As indicated earlier cautious 
interpretation is necessary and additional factors may be operative which determine the observed differences in osteoid volume and calcification front extent values.

The percentage of cases in group III with aluminon positive reactivity is higher that that which would be predicted from group I figures. However, group I cases were different from group II and group III cases as indicated earlier and probably represent too selected a group for valid comparison. The fact that aluminium accumulation does occur in some cases in the face of reverse osmosis fluid dialysis is worthy of note. It is not possible at this stage to determine if these cases will accumulate an aluminium burden which will cause significant disease (cerebral or osseous), but obviously they are cases requiring careful follow-up.

It is emphasised that none of the cases in the present study had either symptomatic bone disease or a dialysis encephalopathy syndrome since patients with the latter were specifically excluded. The important conclusions of the present study, therefore, are that significant histological bone disease with demonstrable aluminium occurs in patients who are neither symptomatic nor encephalopathic and that the use of reverse osmosis fluid dialysis (introduced primarily to protect against the development of dialysis encephalopathy) is associated with a decrease in both the incidence and severity of osteomalacic renal bone disease.

We wish to thank Mr $\mathrm{R}$ Moore of the Bone and Joint Laboratory of the Division of Tissue Pathology, IMVS, for the development and performance of the histochemical demonstration of aluminium.

\section{References}

' Kanis J. Osteomalacia and chronic renal failure. J Clin Pathol 1981;34:1295-307.
${ }^{2}$ Parkinson IS, Ward MK, Kerr DNS. Dialysis encephalopathy, bone disease and anaemia: the aluminium intoxication syndrome during regular haemodialysis. $J$ Clin Pathol 1981;34:1285-94.

${ }^{3}$ Cochran M. Aspects of renal bone disease. Aust NZ J Med 1981;11 suppl:33-7.

4 Cournot-Witmer Giulia et al. Aluminium localisation in bone from hemodialysed patients: relationship to matrix mineralisation. Kidney Int 1981;20:375-85.

${ }^{5}$ Smith PS, McClure J. The localisation of aluminium by histochemical and electron probe $x$-ray microanalytical techniques in bone tissue of cases of renal osteodystrophy. $J$ Clin Pathol 1982;35:1283-93.

- Irwin DA. The demonstration of aluminium in animal tissues. Arch Indust Health 1955;12:218-20.

' Faccini JM, Exton-Smith AN, Boyde A. Disorders of bone and fracture of the femoral neck; evaluation of computer image analysis in diagnosis. Lancet 1976;i:1089-92.

${ }^{8}$ Fazzalari NL. An automatic quantitative image analysing computer. Australas Phys Eng Sci Med 1980;3-4:193-8.

- Raina V. Normal osteoid tissue. J Clin Pathol 1972;25:229-32.

${ }^{10}$ Green JR, Margerison AD. Statistical treatment of experimental data. Amsterdam: Elsevier, 1978.

"Ott Susan M, Maloney Norma A, Coburn JW, Alfrey AC, Sherrard DJ. The prevalence of bone aluminium deposition in renal osteodystrophy and its relation to the response to calcitriol therapy. $N$ Engl J Med 1982;307:709-13.

${ }^{12}$ Ellis HA, McCarthy JH, Herrington J. Bone aluminium in haemodialysed patients and in rats injected with aluminium chloride: relationship to impaired bone mineralisation. J Clin Pathol 1979;32:832-44.

${ }^{13}$ Berlyne GM, Ben-Ari J, Pest D, et al. Hyperaluminaemia from aluminium salts in renal failure. Lancet 1970;ii:494-6.

${ }^{14}$ Kovarik J, Graf H, Meisinger V, Stummvoll HK, Wolf A. Influence of phosphate binders on serum aluminium levels in patients on chronic HD. Mineral and Electrolyte Metabolism 1979;2:242.

15 Parkinson IS, Ward MK, Feest TG, Fawcett RPW, Kerr DNS. Fracturing dialysis osteodystrophy and dialysis encephalopathy. An epidemiological survey. Lancet 1979;i:406-9.

${ }^{16}$ McClure J. The demonstration of calcification fronts by in vivo and in vitro tetracycline labelling. J Clin Pathol $1982 ; 35$ : $1278-82$.

Requests for reprints to: Dr J McClure, Department of Histopathology, University Hospital of South Manchester, Withington, Manchester M20 8LR, England. 